\title{
Functional heterogeneity of forest landscapes and the distribution and abundance of the red-cockaded woodpecker
}

\author{
João C.M. Azevedo ${ }^{\text {a }}$, Steven B. Jack ${ }^{\text {b,* }}$, Robert N. Coulson ${ }^{\text {c }}$, Douglas F. Wunneburger ${ }^{\text {d }}$ \\ ${ }^{a}$ Escola Superior Agrária, Instituto Politécnico de Bragança, Qta. Sta. Apolónia, 5300 Bragança, Portugal \\ ${ }^{\mathrm{b}}$ J.W. Jones Ecological Research Center, Route 2 Box 2324, Newton, GA 31770, USA \\ ${ }^{\mathrm{c}}$ Department of Entomology, Texas A \& M University, College Station, TX 77843-2475, USA \\ ${ }^{\mathrm{d}}$ College of Architecture, Texas A \& M University, College Station, TX 77843-3137, USA
}

Received 13 January 1999; accepted 8 April 1999

\begin{abstract}
Red-cockaded woodpecker (RCW, Picoides borealis) populations are greatly affected by the fragmentation of forest habitat through its effect on the dispersal of individuals between active clusters and other areas of the suitable habitat. In order to assess the suitability of a given landscape structure for the maintenance and expansion of RCW populations, land managers need an index that correlates with the bird's awareness of that structure. Rather than assuming that common landscape metrics provide the necessary information, we applied an index of functional heterogeneity to a GIS coverage for the western portion of the Sam Houston National Forest (SHNF) in east Texas, using two observation scales. In contrast to measured heterogeneity, functional heterogeneity incorporates the RCW response to forest structure. The GIS coverage included information on habitat suitability and RCW cluster distribution and size. The analyses indicated that the presence of cavity trees is the most important factor for RCW population maintenance and that fragmentation of the foraging habitat has much less impact. The analyses also indicated that many areas that are currently of high functional importance for the RCW are effectively isolated from one another. This second result has significant implications for the dispersal of individuals between areas of high functionality and thus also the maintenance of the RCW in this forest. The functional heterogeneity analyses can also be used to examine the trade offs involved in managing the multiple wildlife species simultaneously and for examining the effects of various harvesting regimes through time. (C) 2000 Elsevier Science B.V. All rights reserved.
\end{abstract}

Keywords: Dispersal movements; Forest management; Functional heterogeneity; GIS; RCW; Red-cockaded woodpecker; Spatially explicit analysis

\section{Introduction}

The red-cockaded woodpecker (RCW), Picoides borealis, is an endangered species indigenous to the

*Corresponding author. Tel.: +1-912-734-4706; fax: +1-912734-6650.

E-mail address: sjack@jonesctr.org (S.B. Jack). pine forests of southeastern US. Since the passage of the endangered Species Act of 1973, RCW protection and management have been the focus of a considerable research effort (Kulhavy et al., 1995). One prominent research discovery is a detailed definition of the habitat conditions essential for RCW persistence. The spatial distribution of habitat attributes within the forest landscape is of particular importance to the 
maintenance of RCW populations (Conner and Rudolph, 1991; Thomlinson, 1993; Rudolph and Conner, 1994; Thomlinson, 1995, 1996). Specifically, the distribution of habitat units affects both dispersal movements between groups and access to foraging areas (Rudolph and Conner, 1994).

Ultimately, management plans that address the sustained protection of the RCW must embrace a broad spatial extent and deal explicitly with both the content and context of landscape structural elements (Forman, 1995; Turner et al., 1995; Coulson et al., 1996). Such investigations, however, must consider the spatial arrangement of suitable habitat units at a scale and perspective relevant to the RCW (Cale and Hobbs, 1994). Landscape structure is often summarized and represented as heterogeneity. Although defined in several ways, the term heterogeneity is generally taken to mean variation in the composition of landscape units in space and time. The landscape elements examined, however, are generally physical features or components chosen independently of the organism of interest (i.e., measured heterogeneity; Kolasa and Rollo, 1991). In this study, we are interested specifically in the functional heterogeneity (Kolasa and Rollo, 1991) of the forest landscape by including the information on how the RCW perceives and responds to variation in its environment. The functional heterogeneity approach, as opposed to measured heterogeneity, thus, incorporates the context as well as content of landscape elements by considering how the specific arrangement of landscape elements enhances or inhibits RCW demography and behavior.

The existing information on RCW behavior and habitat requirements forms the foundation for a landscape-level investigation of the RCW in a forest landscape mosaic in east Texas. Our goals are to consider the relation of landscape structure with the distribution and abundance of the RCW, and to suggest methods for interpreting study results for management purposes. The specific objectives are: (i) to investigate the distribution and abundance of RCW clusters in relation to the functional heterogeneity of the forest landscape; (ii) to examine the persistence of the RCW in the context of forest landscape functional heterogeneity; and (iii) to evaluate the implications of study results within the context of forest management practices.

\section{Study area}

The western portion (i.e., the former Raven District) of the Sam Houston National Forest (SHNF) located in Walker and Montgomery Counties of southeast Texas (bound by $95^{\circ} 56^{\prime} \mathrm{W}, 30^{\circ} 26^{\prime} \mathrm{N}$ and $95^{\circ} 22^{\prime} \mathrm{W}, 30^{\circ} 45^{\prime}$ $\mathrm{N})$ was the area of focus for this study. This area encompasses approximately 66,000 ha and contains the majority of RCW clusters in Texas, and has one of the higher density RCW populations in the species range (Conner et al., 1997a). While habitat quality is enhanced by the generally contiguous nature of the area's forests (approximately 39,200 ha are not impacted by the fragmentation of ownership or nonforest land use), examples of the effects of landscape fragmentation are also evident due to the many private in-holdings typical of the southern National Forests. Adjacent private holdings, typically, are managed for pasture or short-rotation pine plantations and do not provide a suitable habitat for the RCW.

National Forest holdings within the SHNF are managed under a hierarchy of compartments and stands. The 79 compartments in the study area are composed of stands that average 19.25 ha in size (range 0.1-537 ha). The dominant tree species is loblolly pine, Pinus taeda L., but some shortleaf pine (Pinus echinata Mill.) is also present. Most stands $(87 \%)$ are composed of pine trees less than 80 years of age, and approximately $1 \%$ of the stands contain Pinus trees greater than 100 years of age.

The 125 active RCW clusters within the study area exist mostly within contiguous forest areas. Active clusters consist of one to eight (mean $=3.2$ ) cavity trees, providing an average density of 314 ha total forest or 285 ha pine forest per active cluster. Twenty percent of the active clusters consist of only one cavity tree, $43 \%$ contain two or three, and $37 \%$ contain four or greater cavity trees. There are also 85 inactive clusters in the study area; these clusters have cavity trees but no nesting activity as of the last survey. The majority of the active cavities are of natural origin, but artificial cavities also have been installed.

The Forest Service also employs replacement and recruitment management practices. Replacement areas $(N=208)$ are located close to the existing active clusters and provide the required nesting and roosting habitat conditions in case the cluster of cavity trees is destroyed. Recruitment areas $(N=74)$, on the other 
hand, possess similar habitat conditions as replacement areas but are located in unpopulated or low RCW population density regions in order to attract new birds to these regions. Both replacement and recruitment areas are nominally 4 ha in size.

\section{Methods}

\subsection{Stand-level data}

Data obtained from the National Forests and Grasslands in Texas consisted of GIS stand coverages and hard copy tables concerning RCW cluster locations and characteristics. Associated data were extracted from the Continuous Inventory of Stand Conditions (CISC) data base and joined with the GIS coverages to develop spatially referenced stand attribute tables. Relevant CISC fields and tabular data for RCW clusters were related by stand number, stratified by compartment, and joined to create vector coverages depicting the spatial representation of timber stands within the study area. Upon completion of the vector coverage, a multi-layered grid representation of the area was created using 1 ha cells $(100 \mathrm{~m} \times 100 \mathrm{~m})$.

Comprehensive coverage of the study area by representative data was far from complete. As stated earlier, private in-holdings within the SHNF occur with regularity, but data describing these in-holdings were not available. Often, records in the GIS coverage or CISC data base lacked complete sets of attributes. Therefore, comprehensive stand data were not available for the entire study area, even on National Forest land. In addition, replacement and recruitment stand boundaries did not always coincide with timber stand boundaries; consequently, the compartment and stand numbers specifying RCW cluster locations in the CISC data base were not always consistent with the stand enumeration followed in the GIS coverages.

In order to utilize the available information, the data base was modified interactively to include values for missing fields or unmatched records, and steps were taken to ensure that errors due to these inconsistencies were minimized. National Forest and private lands lacking timber stand information were categorized according to a series of assumptions ranging from completely beneficial to completely non-beneficial for RCW habitat (approaches 1-3 given below); transla- tion of the data in this manner had the effect of illustrating the impacts of various levels of landscape fragmentation and subsequent effects on functional heterogeneity for the RCW.

\section{2. $R C W$ habitat suitability classification}

In order to complete the functional heterogeneity analysis, accurate knowledge of RCW population behavior with respect to habitat is required. Assuming the presence of sufficient RCW foraging habitat, the distribution and spatial dynamics of the population are dependent primarily on the following factors: nesting and roosting habitat quality, habitat used by individuals for movements, locations of currently active clusters, and the spatial distribution and configuration of these units (Walters, 1991; Thomlinson, 1996; James et al., 1997). The functional heterogeneity indices seek to describe, at any point in the forest, the quality of the habitat as perceived by the RCW in relation to the presence or absence of these required landscape components.

The classified habitat units were ranked (using an ordinal scale) for preference by the RCW, independent of their accessibility in spatial terms. Landscape-scale spatial relationships between stands was assessed by calculating specific functional heterogeneity indices (discussed below) for the classified GIS coverage after including additional information about the location and group size of RCW clusters. Therefore, habitat quality rating was affected by the presence or absence of clusters in the landscape.

Due to the lack of complete stand structural data for many of the timber stands in the data base, three approaches, which differed primarily in the classification of stands with incomplete data, were utilized for habitat suitability classification. These approaches are described below.

\subsubsection{Approach 1}

The dependency of the species on existing cavity trees has strong implications in terms of the definition of its suitable habitat. That is, a cluster of cavity trees, even if inactive, has a high value in terms of potential nesting habitat for the RCW (Walters, 1991; James et al., 1997). Thus, stands containing active or inactive cavity trees were classified with the highest suitability habitat values: active clusters were assigned a value of 
7; and inactive clusters, including those with artificial cavities, were assigned a value of 6 . Replacement and recruitment stands are managed specifically to provide suitable conditions for nesting and roosting habitat, so these areas were classified as class 5 habitats. The next suitability classes were based on the age of the stands, provided that the forest type was loblolly or shortleaf pine and the stand condition was mature or immature sawtimber. An age of 60 years was set as the limit of suitability of pine stands for RCW nesting and roosting, based on our data set and a study conducted by Thomlinson $(1993,1995)$ in the same area. Stands older than 100 years were classified with a value of 4 ; stands 80-100 years old were classified with a value of 3 ; and stands with ages ranging from 60 to 80 years were classified with a value of 2 .

It was assumed that RCW individuals prefer to move within the pine forest because they display reluctance to cross open areas when they do not know what there is on the other side (Conner and Rudolph, 1991). The stands unsuitable for nesting and roosting but suitable for foraging habitat represent conditions favorable for the movement of individual birds. The lowest class of habitat suitability was, therefore, defined by stands of loblolly and shortleaf pine with ages above 16 years. This threshold age was chosen based upon the results of DeLotelle et al. (1987) in central Florida. All remaining stands in the study area, including those with no available stand age information, were assigned a habitat suitability value of 0 (completely unsuitable). (Note: the habitat classification scheme is ordinal, and a habitat value of 6 is not necessarily twice the quality of a value of 3 ).

To summarize approach 1, no stand structural data other than the presence or absence of cavity trees and tree age were considered. Implicit in this approach is the assumption that the stand structures presently unsuitable for nesting and roosting (e.g., those with too much midstory vegetation but trees older than 60 years) can be made suitable through the application of various vegetation management techniques.

\subsubsection{Approach 2}

This approach followed the scheme defined in approach 1, but basal area was included as an additional criterion for classification. Stands in the SHNF with total basal area above $25 \mathrm{~m}^{2} /$ ha or hardwood basal area above $4.5 \mathrm{~m}^{2} /$ ha were shown to be restric- tive in terms of habitat suitability for the RCW (Thomlinson, 1993). Thus, for approach 2, areas with total and hardwood basal areas above these threshold values were considered appropriate only for foraging habitat (suitability class 1 ), regardless of age, as were stands where basal area data were missing.

\subsubsection{Approach 3}

This was the most restrictive approach: those stands that did not have structures suitable for nesting and roosting (whether due to tree age or basal area) were considered as unsuitable for any RCW activity (suitability class 0 ). In addition, stands that had no information concerning basal area were excluded from suitable RCW habitat, regardless of tree age.

The range of approaches, in essence, provides a sensitivity analysis for the effect of habitat fragmentation on functional heterogeneity because the three different approaches define the range of likely characterizations of the forest pattern in the SHNF. Approach 1 (Fig. 1(a)) represents the best possible landscape-level habitat for the RCW, assuming that considerable vegetation management occurs to produce suitable structural characteristics, whereas approaches 2 and 3 (Fig. 1(b) and (c), respectively) are probably closer to the existing conditions.

\subsection{Combination of habitat suitability and $R C W$ information}

Additional information about the RCW was incorporated into the habitat suitability maps using the group size variable. The number of active cavity trees in each stand provided an indication of group size. Three classes for group size were considered: class 0 (one active cavity tree); class 1 (two or three active cavity trees); and class 2 (four or more active cavity trees). This additional information, thus, affects only the previously defined habitat suitability class 7 (active clusters). We assume here that large groups have more potential for the dispersal of birds, particularly fledgling females, than small groups (Lennartz and Harlow, 1979; Conner and Rudolph, 1989).

Final habitat/RCW maps were obtained by summing each of the three habitat suitability grid layers (from the approaches described above) with the group size layer to obtain a classification system based on 10 classes (values $0-9$ ). These habitat/RCW grids 
(a)

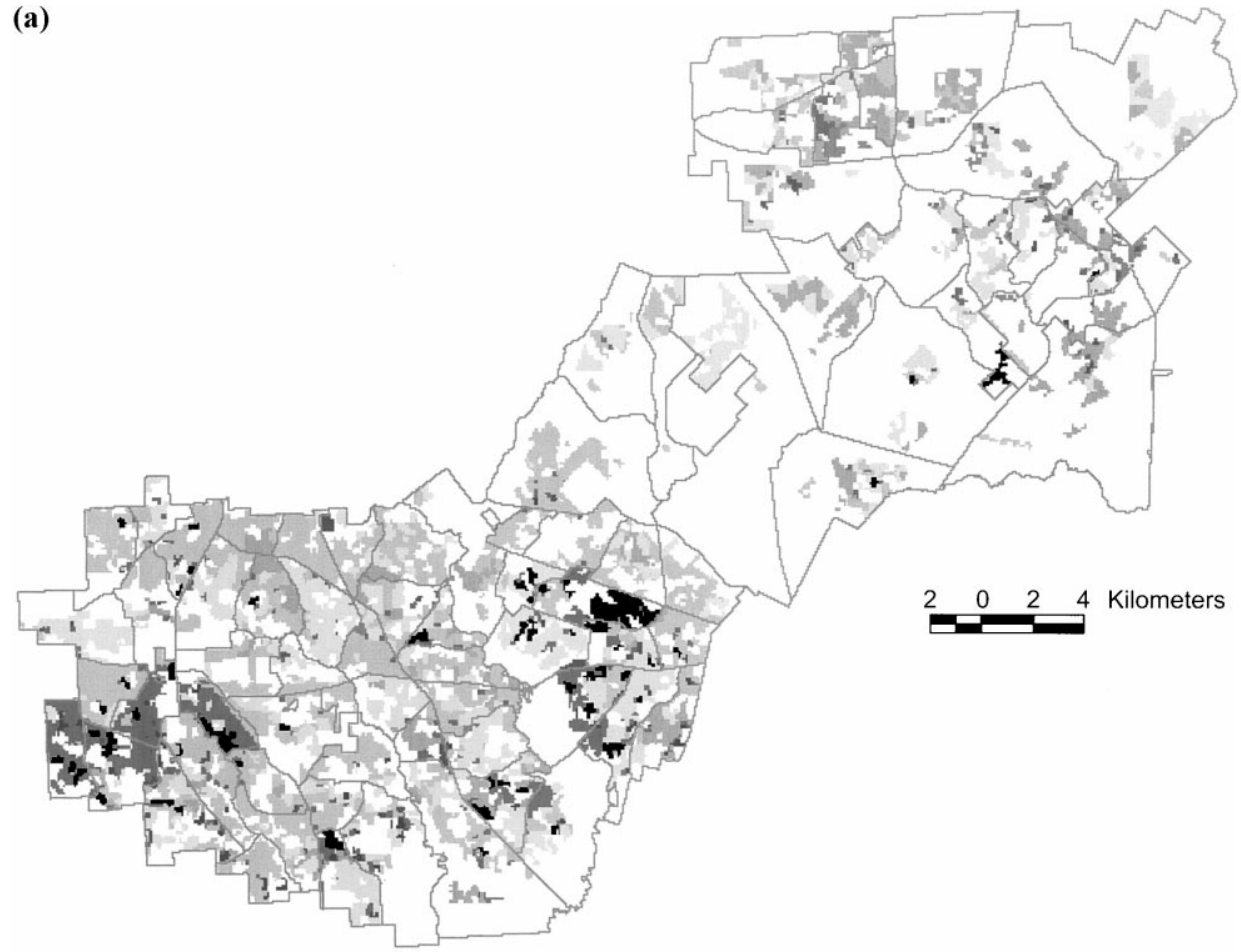

(b)

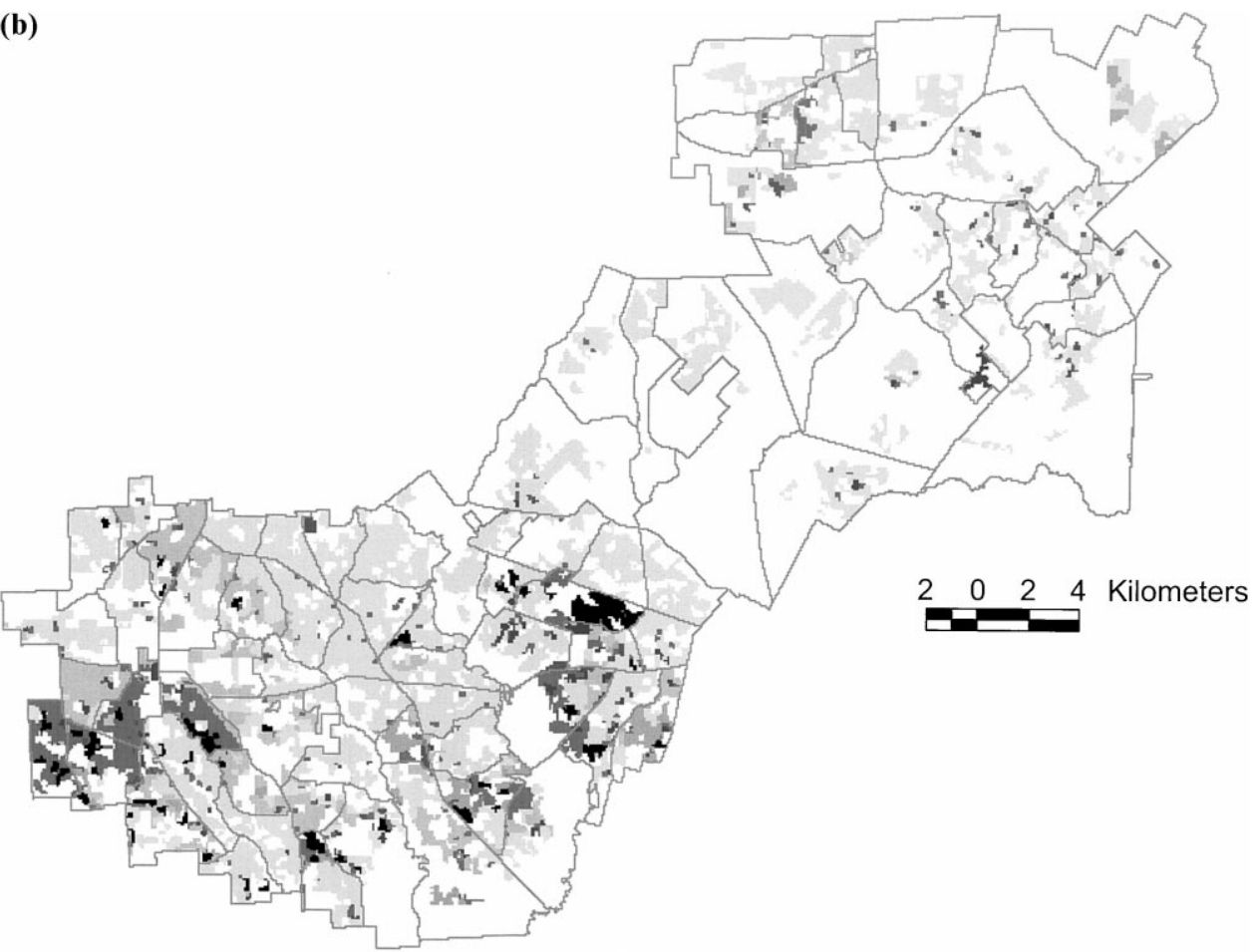

Fig. 1. Habitat suitability coverages for the western portion of the SHNF under: (a) approach 1, (b) approach 2, and (c) approach 3. 
(c)

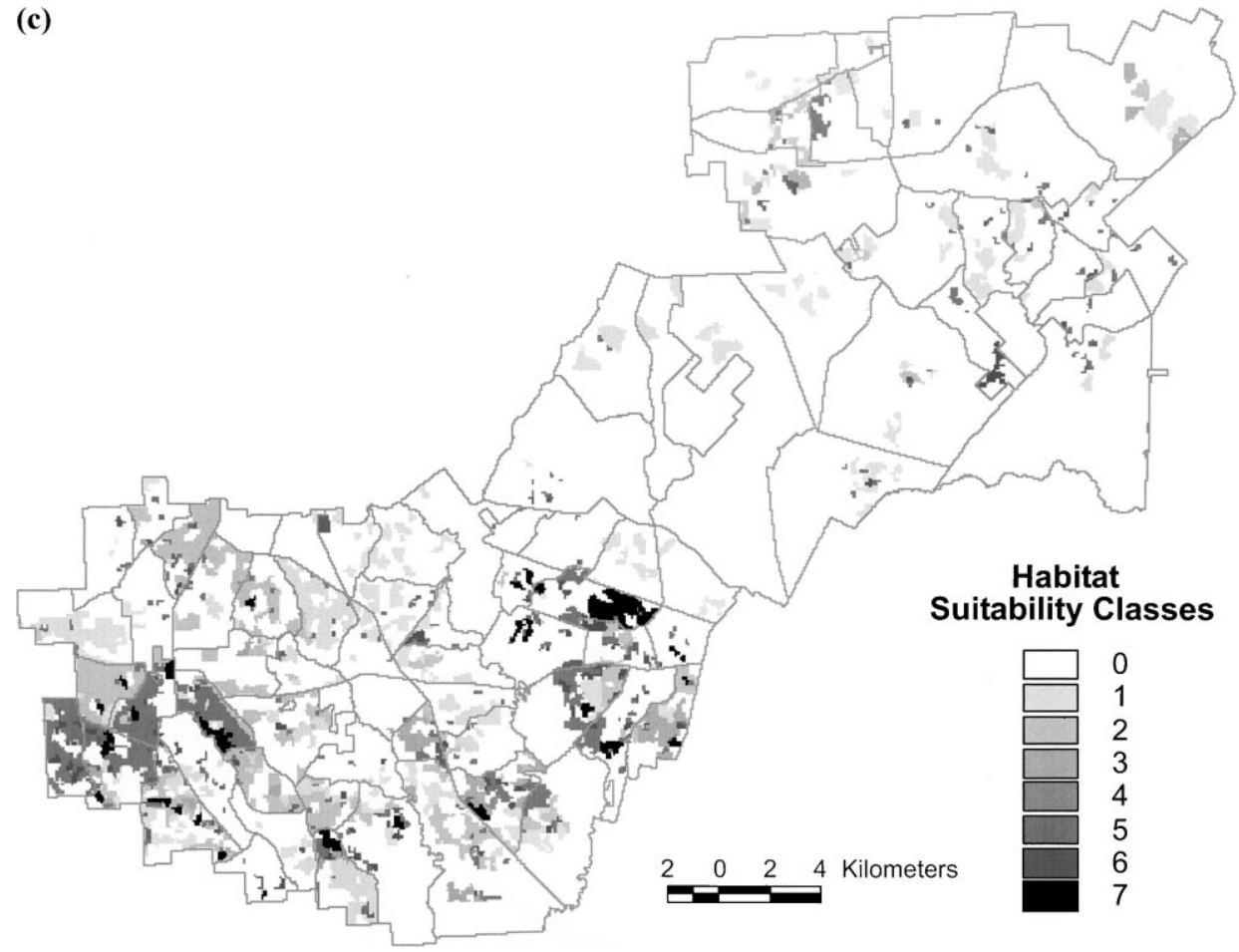

Fig. 1 (Continued).

constitute the matrices submitted to the algorithms which calculated the functional heterogeneity indices.

\subsection{Functional heterogeneity indices: description and application}

Functional heterogeneity is a useful concept in defining connected landscape units because, as Cale and Hobbs (1994) suggest, it is necessary for a truly informative index of habitat heterogeneity to integrate landscape structure with the demographic processes and behavior of animals. To evaluate the functional heterogeneity of the study area, we used three indices of functional heterogeneity created and adapted by Coulson et al. (1996). In order to simplify the presentation, however, only one index, Weighted Connectivity (WH), will be discussed here. $\mathrm{WH}$ is sensitive to the linear connectedness of the most valuable landscape elements (Coulson et al., 1996).

Values for WH were calculated using a moving window function which calculates the index for each cell in the input GIS grid using the values of a constant number of cells (i.e., a submatrix) in the neighboring region. WH is calculated by summing 'run-lengths' (the number of sequential cells with equal habitat value) along rows, columns and diagonals centered on the cell of interest in the submatrix formed by the moving window. Thus, the size of the window (i.e., the number of cells in the submatrix) determines the scale of the functional heterogeneity examined. Details for the computation of $\mathrm{WH}$ are provided in Coulson et al. (1996).

Mean dispersal distances of RCW individuals were used to establish two window sizes for examination. As distances flown by the RCW in the area of study were unknown, flight distances measured by Walters et al. (1988) in north Carolina were used: a window size of $4.1 \mathrm{~km} \times 4.1 \mathrm{~km}(41 \times 41$ cells $)$ represents the distances flown by fledgling females, the most important group in terms of the dispersal movements and maintenance of RCW populations, while a $2.1 \mathrm{~km} \times 2.1 \mathrm{~km}(21 \times 21$ cells $)$ window incorporates the movements of adult females. The $4.1 \mathrm{~km} \times 4.1 \mathrm{~km}$ window also approximates the average male dispersal 
distance (4.5 km; Walters et al., 1988). Using two window sizes allowed the examination of scale effects on the functionality of the habitat for the RCW. While longer dispersal distances have been documented recently (Conner et al., 1997b; Ferral et al., 1997), the window sizes used in the analyses encompass the short dispersal distances more typical of the species.

The combined habitat/RCW grids were converted into ASCII files in Arc/Info ${ }^{\circledR}$ and used as inputs for the calculation of the functional heterogeneity indices. FORTRAN programs (P.E. Pulley, personal communication), first used in the study of the relationship between bark beetles and forest pattern (Coulson et al., 1996), were adapted to the grid size and window sizes used in this project. The SGI Power Challenge super computer located at the Texas A \& M University was used to carry out the calculations.

The algorithm produces a continuum of values for the three functional heterogeneity indices, making distinction between areas difficult and meaningful visualization nearly impossible. Therefore, output values for the functional heterogeneity indices were grouped into classes, dependent on the range of values obtained, for mapping and analysis. Calculated zero values were considered as a separate class.

\section{Results and discussion}

\subsection{High functionality areas indicated by the overall results}

The high-value (i.e., high functionality) areas (numbered in Fig. 2 to facilitate reference) are almost always located around the same group of compartments, though their extent and the absolute values obtained for WH change from approach to approach and between window sizes. These areas are located in the north (I), west (II), and east (III) of the southwestern region of the study area (Fig. 2). A smaller,

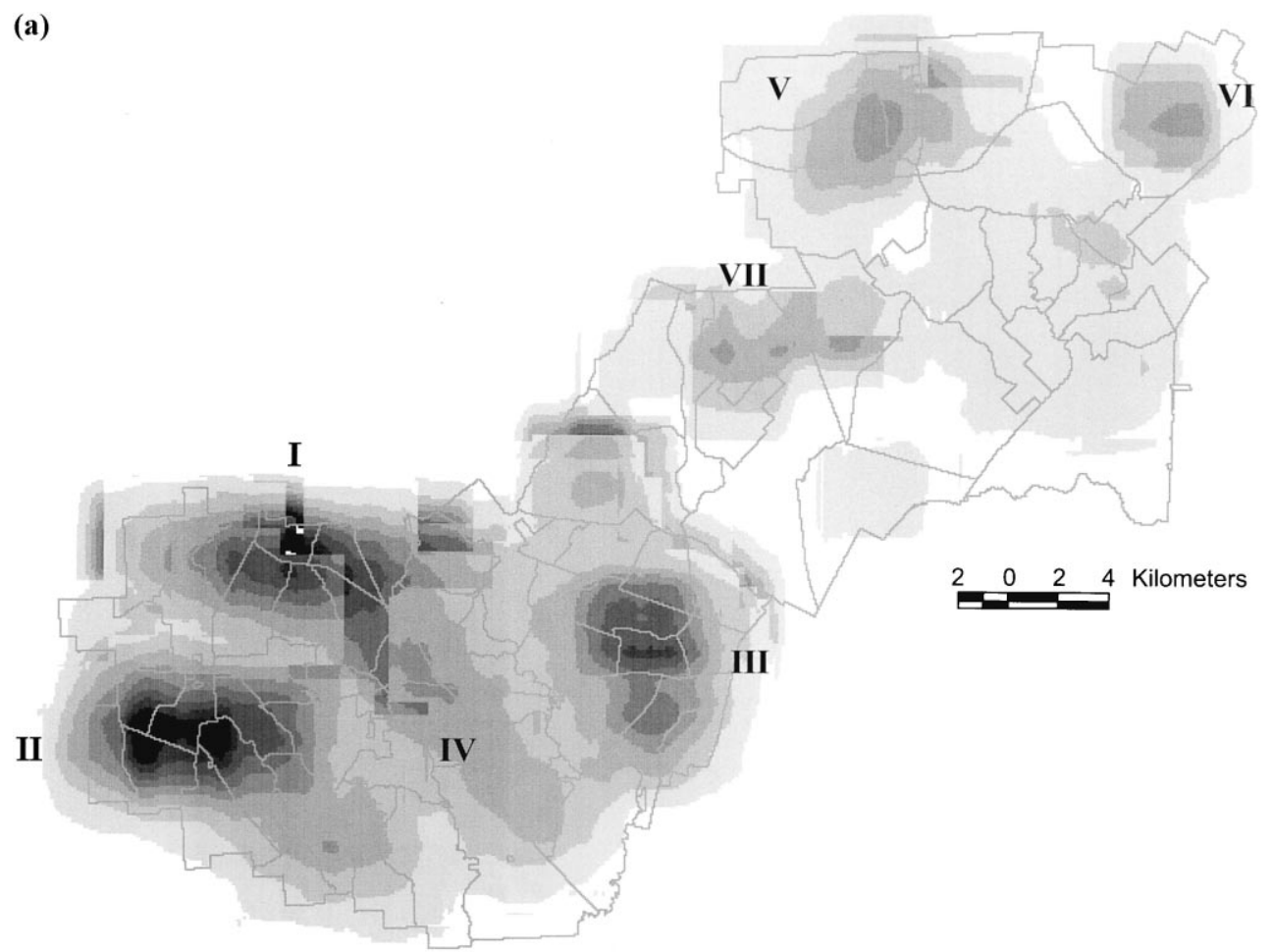

Fig. 2. Results for the WH index for functional heterogeneity using $41 \times 41$ cell moving window. Analysis of fragmentation represented by (a) approach 1, (b) approach 2, and (c) approach 3. 
(b)

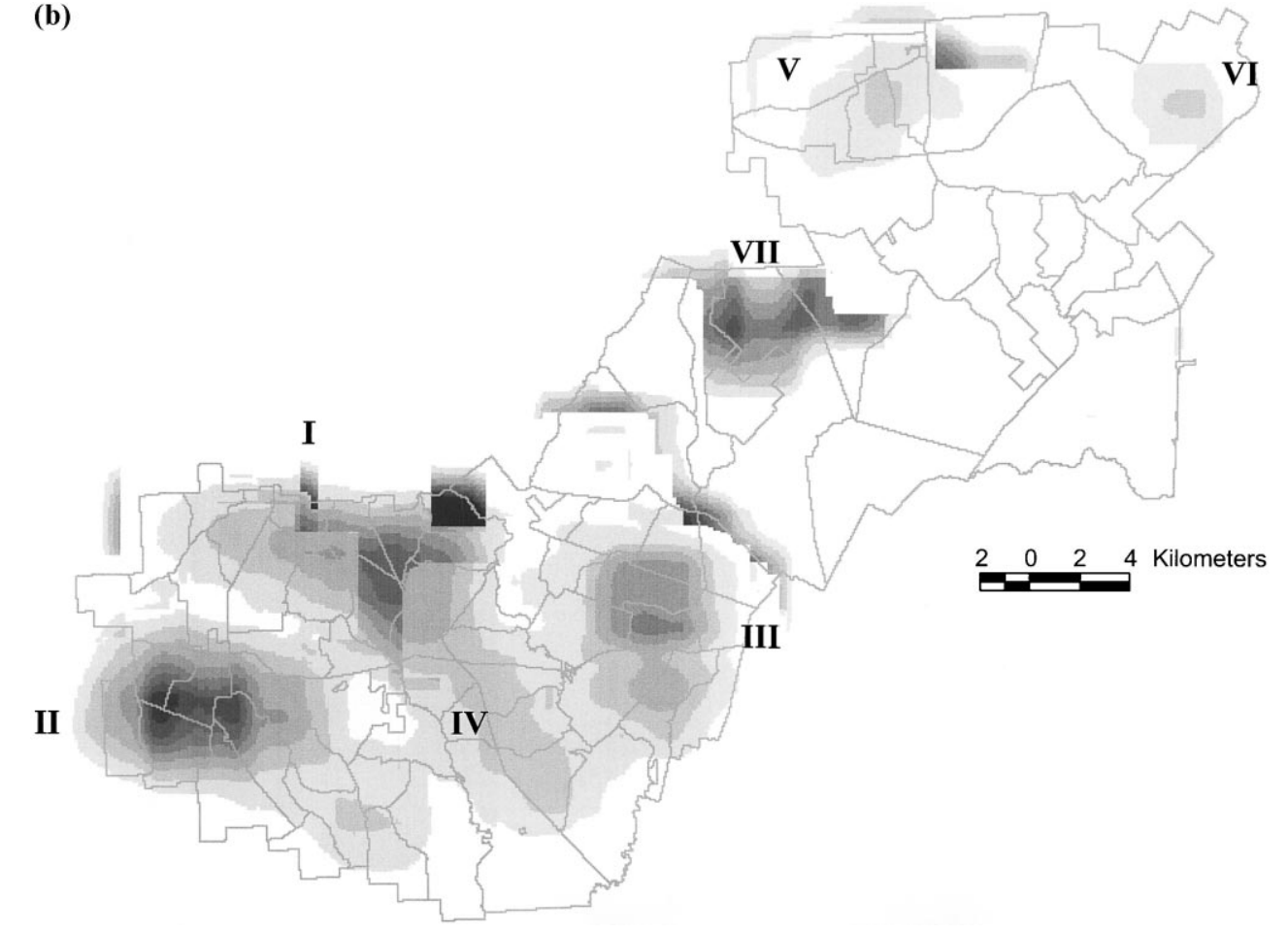

(c)

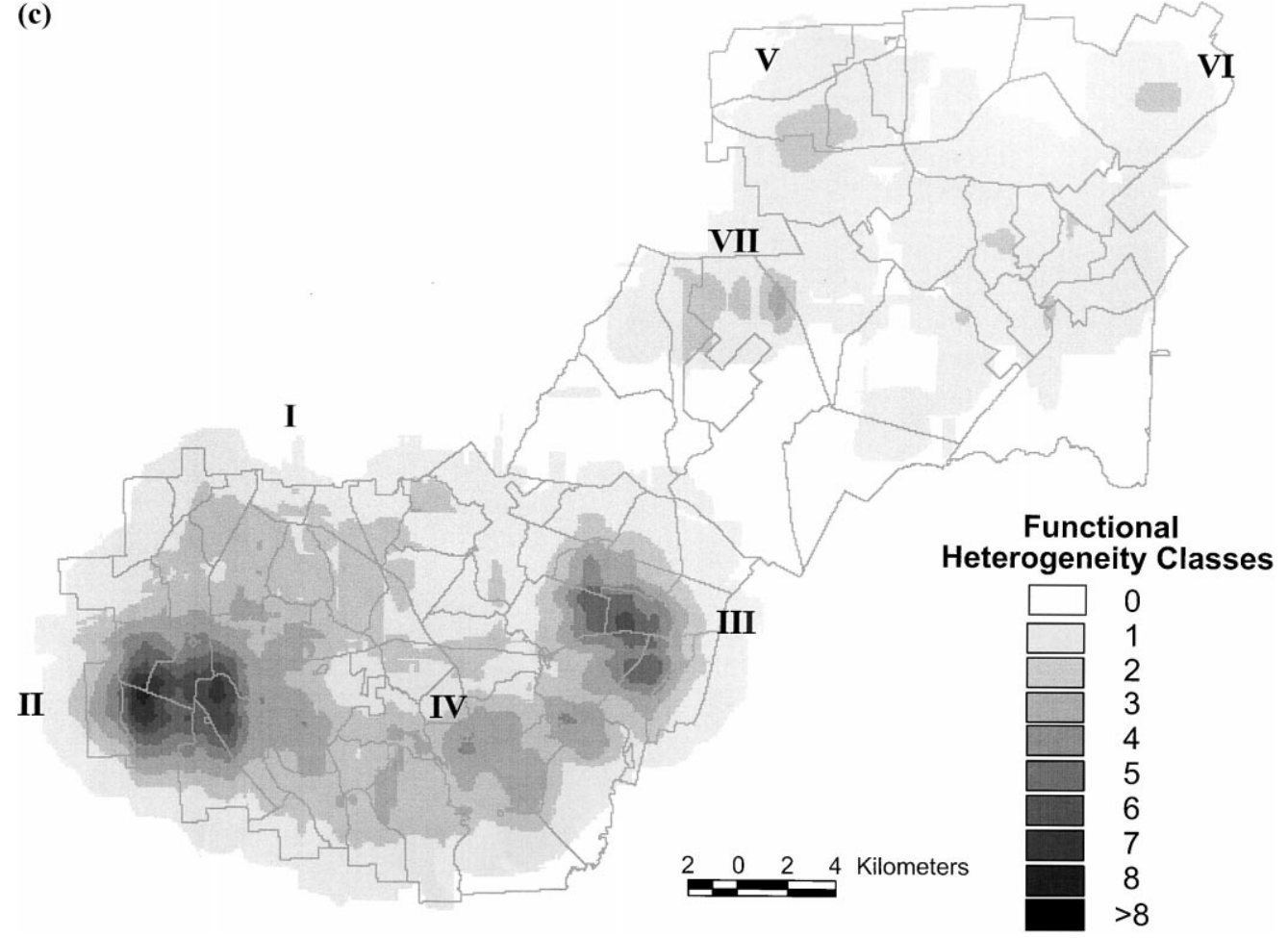

Fig. 2 (Continued). 
central area (IV) is also detected in many, but not all, cases. The northeastern region of the district is more difficult to characterize since the areas of high values are not as constant. There are, however, areas in the northwest (V), northeast (VI) and west (VII) of this region which are detected frequently, especially when using approach 2 (Fig. 2(b)).

Though specific areas are indicated as having high functionality, the conditions that generate high index values are quite different between locations. The areas with high functionality (as indicated by WH) always have a reasonable abundance of cells with habitat/ RCW values of at least 5 located within larger areas of cells with values 1,2 , and 3 . Area I is a case in point: in this area, the highest habitat/RCW value is 5 , yet with the $21 \times 21$ window size high values for WH were calculated (Fig. 3). Slightly different results are found for the larger $41 \times 41$ window size, however; in this case, area I loses importance in terms of functionality, as indicated by $\mathrm{WH}$, as the concentration of high value cells decreases from approach 1 to approach 3 (Fig. 2). This result indicates two things: the WH index is sensitive not only to the presence of high input values but also to their density; and, similarly, the $41 \times 41$ window size appears to be more sensitive to both the presence and density of high-value landscape elements than is the $21 \times 21$ window size.

The areas detected by WH as having high functional heterogeneity are generally coincident with the major aggregations of active clusters, but not exclusively so. The zones of high index values in areas without active clusters are indicative of the limits at which the index can operate; i.e., WH is able to detect areas with suitable habitat for the species even when the species is not present. The northern area (area I) of the southwestern region is the primary example of that ability. In fact, this area had higher index values than some areas containing active clusters. In addition, some concentrations of active clusters were not detected as being functionally important by the index. Such groups are located in areas of poor landscape conditions for the species, or they are small in size and isolated from other groups of clusters by unsuitable habitat. In one sense, the high WH values found for areas with active clusters or suitable nesting and roosting structure are not surprising, given the high classification values for such a habitat; on the other hand, high WH values are calculated only when there is a significant concentration of high value elements in the array, and small isolated patches with high classification values still have low functionality according to the WH index (e.g., the active clusters with low functionality mentioned above). It is this second characteristic of the WH index that makes it particularly useful for examining landscape-scale spatial relationships for the RCW.

\subsection{Effects of fragmentation}

Fragmentation increases the abundance of the lowest values in the habitat/RCW input grids ( 1 or 0 according to the type of fragmentation considered; Fig. 1). Fragmentation greatly reduces the values obtained for $\mathrm{WH}$ since this index is sensitive to the presence of zero values in the input matrices.

The increased fragmentation between approaches 1 and 2 does not seem to substantially disrupt the actual pattern of functional heterogeneity for the RCW in the study area. That is, the areas more important for the $\mathrm{RCW}$ in the less fragmented situation, approach 1, are generally maintained in approach 2 . The small degree of change between the two approaches is due to the decrease in potential nesting and roosting habitat with approach 2, while the stand conditions required for movement still exist in the foraging habitat.

Fragmentation in terms of absolute loss of habitat as incorporated in approach 3 reveals that some change in the pattern of functional heterogeneity would occur at the level of the landscape, but many of the highvalue areas detected by approach 1 are still maintained. In fact, there were few changes in the location of the areas with the highest values for $\mathrm{WH}$ as fragmentation increased from approach 1 to approach 3. The primary change as fragmentation increased between the approaches was the loss of area I as an area with high functionality (Figs. 2 and 3).

Increasing fragmentation also leads to increased isolation of high-value areas, both within and between the two regions of the study area (Figs. 2 and 3). As fragmentation increased from approach 2 to approach 3 , the northeastern region is completely isolated from the southwestern region by an extensive area of unsuitable habitat (index values of zero). Within the northeastern region, the habitat is fragmented into small islands of suitable habitat with functional heterogeneity values only slightly above zero. In the 
(a)

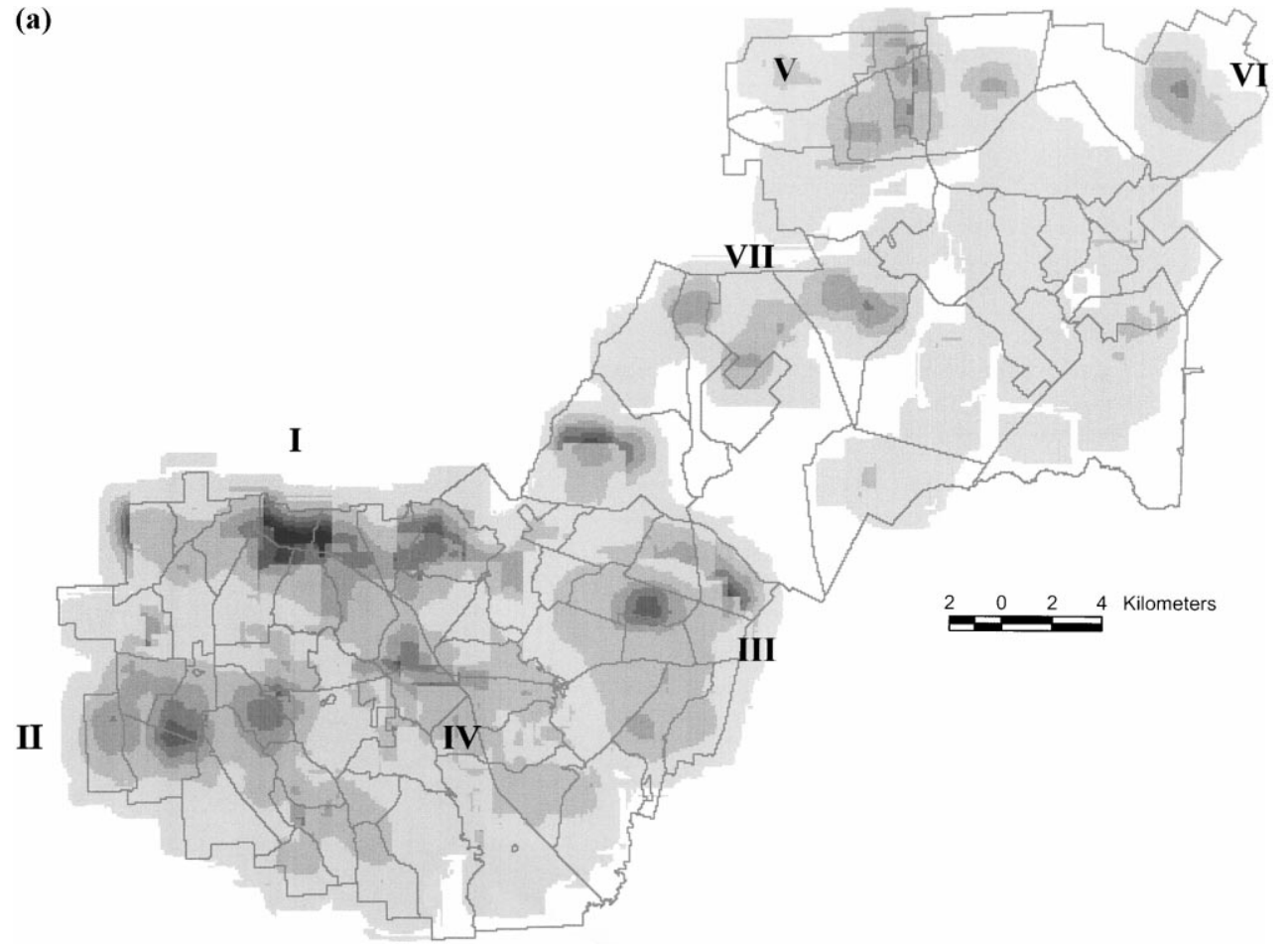

(b)

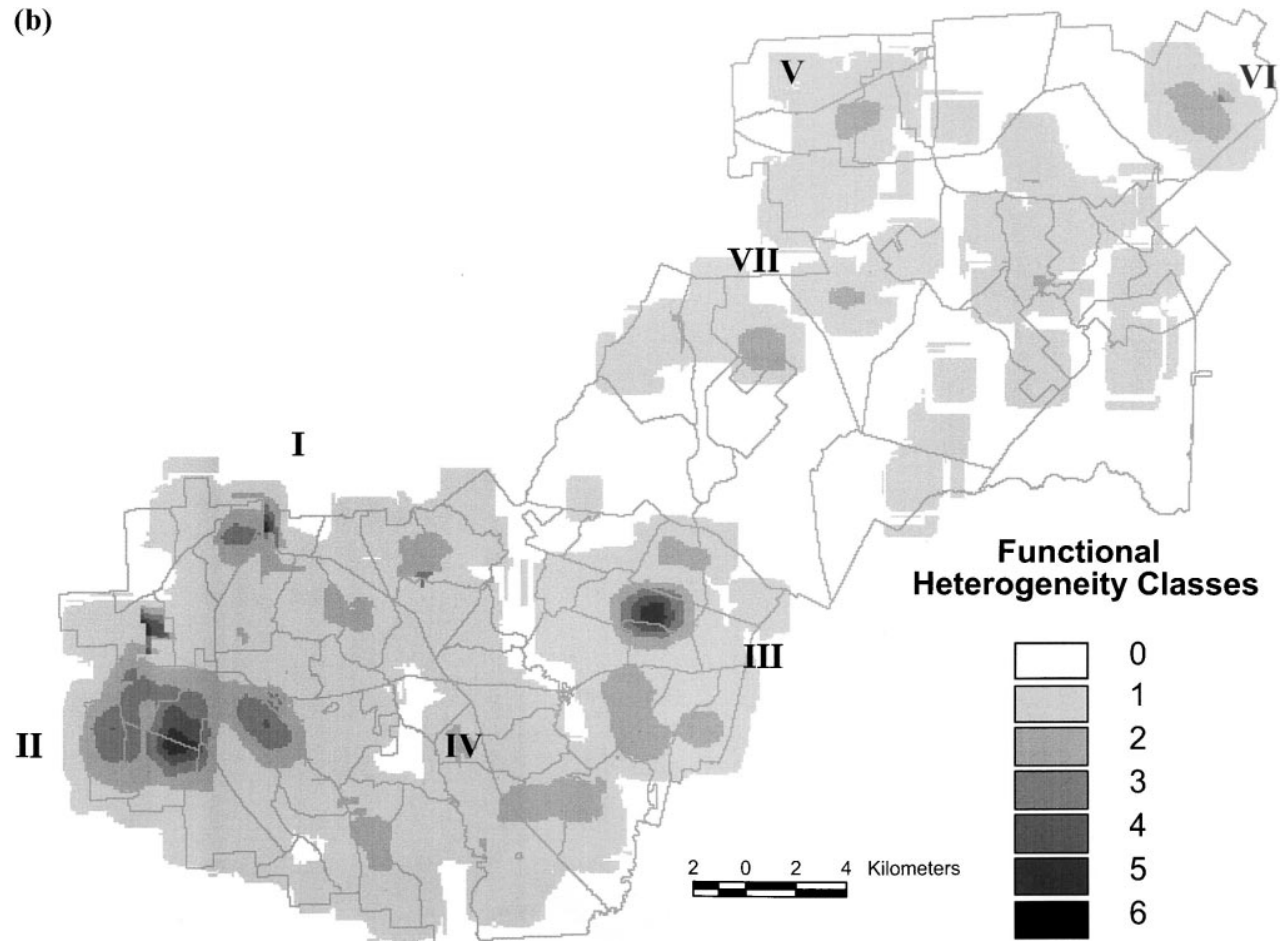

Fig. 3. Results for the WH index for functional heterogeneity using $21 \times 21$ cell moving window. Analysis of fragmentation represented by (a) approach 1 and (b) approach 3. 
southwestern region, area III becomes isolated from the areas I and II by a large strip of low or zero values (particularly with the $21 \times 21$ window), and the central area (area IV) no longer has high values for WH.

It is expected that the areas that maintain high WH values as fragmentation increases are also those with the best chance for maintenance of the RCW population. This means that the areas with high functional heterogeneity values for all three approaches provide the most favorable conditions for the species, regardless of the degree of fragmentation created (which was quite intense in the third approach). In this sense, it appears that the western (II) and eastern (III) areas of the southwestern region are least affected by the levels of fragmentation expressed in approaches 2 and 3 , and the main nuclei of RCW populations would be maintained in these areas. Active clusters located outside the areas defined by high $\mathrm{WH}$, however, will have a tendency to disappear since there are no conditions suitable for contact with other clusters, and inactive clusters located outside these same high-value areas will not be recolonized.

\subsection{Management implications}

The functional heterogeneity analyses provide a landscape-level, quantitative assessment of habitat suitability in terms of how the RCW is likely to respond to the forest structure. That is, the analyses consider the study area as a whole rather than examining the forest on a stand-by-stand basis. Because the functional heterogeneity analysis indicates which portions of the landscape support the most stable subpopulations (thereby acting as a potential source population), as well as indicating which subpopulations are isolated, and therefore prone to disappearing, they provide useful information for managing the habitat to maintain the population of interest. Several management aspects, divided into those dealing strictly with conservation of the RCW and those involving more comprehensive management goals, are discussed below.

\subsubsection{Maintenance and expansion of $R C W$ populations}

The analyses for functional heterogeneity provide an indication of the areal extent of highly functional habitat in the landscape. This consideration is impor- tant because, knowing the minimum area necessary to sustain a cluster (e.g., James et al., 1997), the carrying capacity for a particular area can be calculated. Large areas with high functionality that are not fully occupied could be useful for accepting additional birds that have to be moved from other locations. The larger subpopulation would likely then be more stable and would have a greater potential to expand into surrounding areas if suitable habitat becomes available.

The functional heterogeneity analyses also indicate parts of the landscape where supplementation, both in terms of artificial cavities and introduced breeding pairs, is a viable alternative. Given the successful use of artificial cavities (Walters, 1991; Walters et al., 1992), areas which have all other necessary habitat and landscape conditions could have their functionality greatly improved through installation of the manmade nesting cavities. The introduction of artificial cavities can be used alone or in conjunction with the introduction of breeding pairs into a particular area, a process which has also shown some success (Rudolph et al., 1992). These supplementations should be focused on areas that have medium to high functional heterogeneity indices so that the birds have the greatest probability of survival and can serve as new centers for dispersal. Conversely, areas of the landscape that have suitable habitat but are functionally isolated (as indicated by the analyses) should not be supplemented due to low expectations for long term viability of cavity colonization or survival of introduced groups.

Efforts to enhance connectivity can be directed by functional heterogeneity analysis as well. As the dispersal of individuals between clusters is critical for the maintenance of populations in the landscape, areas with high functionality should, ideally, be connected by habitat suitable for the movement of birds. Connectivity is also important for the expansion of the population into areas with suitable habitat but few or no birds. Some areas with high functionality may be too small to remain viable in isolation but may serve as 'stepping stones' to maintain connectivity between larger areas with high functionality. Area IV in Fig. 2(a) and Fig. 3(a) may represent such a case. Under the greatest landscape fragmentation, area IV no longer has high functionality due to isolation (Fig. 2(c) and Fig. 3(b)). If less fragmentation is maintained in the landscape, however, the area may help to increase the connectivity between areas II and III. 
The practices of supplementation and maintenance of connectivity are complementary and can be used together to more rapidly expand RCW populations. That is, the supplementation can be used most effectively to link areas with currently high functionality, and thereby, increase the connectivity between population centers. Such a strategy could create an overall network, facilitating movements and contacts between woodpeckers from different clusters.

\subsubsection{More 'comprehensive' management questions}

The functional heterogeneity analysis is not limited to the study of RCW conservation practices, but can also be used to address broader management questions. For instance, by calculating the functional heterogeneity of a forest landscape for several different species occupying the same area, we can examine whether there are compatibilities or conflicts in terms of the habitat required and the resulting functional heterogeneity, in managing for the different species simultaneously. Such multiple analyses could be used to examine the viability of managing for multiple endangered species or to determine if endangered species management is compatible with management for game species or management for reducing pest outbreaks. For example, there is some evidence that stand structures with high functionality for the RCW are also attractive for the southern pine beetle (Coulson et al., 1995; Rudolph and Conner, 1995). By comparing results for functional heterogeneity for the two organisms, we can judge whether management for the endangered RCW may lead to problems with beetle outbreaks. If such conflicts are indicated by the functional heterogeneity analyses, then trade offs can be examined and forest management adapted appropriately.

Functional heterogeneity analysis provides an indication of the landscape suitability for the species of interest for a single point in time, but areas currently possessing high functionality may not remain in that state indefinitely. By incorporating various assumptions, however, functional heterogeneity analysis can be combined with different types of simulation models to judge better the effects of forest management or natural stand dynamics on a species through time. To assess the effects of no active management, the output of forest succession models could be analyzed to determine if the species of interest will survive for an extended period of time with no human intervention. For areas with active management, the output from harvest scheduling models could be analyzed to see how the species of interest might respond to harvests of different intensities or those that are arrayed across the landscape in different ways. Conceivably, this sort of analysis could be used to determine what sort of harvest configuration (e.g., boundary complexity or size of area harvested) is most beneficial or detrimental to the species of interest. Finally, the analysis of model output could be carried out for multiple species simultaneously, as outlined above, to determine the management regime that best balances the requirements for all species of interest.

\section{Conclusions}

Based on the results of this study of functional heterogeneity for the SHNF, we reach the following conclusions:

1. The functional heterogeneity indices seem to be an effective way to detect areas of the forest most important for the maintenance of RCW populations. The generated information provides not only increased understanding of the ecology of the species but also useful guidelines for management practices to maintain the population. Perhaps, most importantly, the functional heterogeneity analyses provide a landscape focus to guide management rather than focusing on individual clusters or stands.

2. Fragmentation of the kind expressed by approach 2 (i.e., fragmentation of the nesting and foraging habitat) does not appear to greatly alter the spatial conditions within the areas detected as most important for the species. On the other hand, fragmentation of the kind expressed by approach 3 (i.e., severe fragmentation of the total area) leads to only a few main centers of high functional heterogeneity for the RCW remaining in the study area, and these are isolated from one another.

3. Functional heterogeneity analysis can be extended to examine more comprehensive management questions. For example, combined analyses for multiple species can indicate potential conflicts 
in management strategies for the individual species. Alternatively, functional heterogeneity analysis can be integrated with harvest scheduling techniques to examine the longterm effects of various harvest strategies over large areas on the species of interest.

\section{Acknowledgements}

We thank P.E. Pulley, Texas A \& M University, for modification of the routines to calculate functional heterogeneity; R.N. Conner and D.C. Rudolph (US Forest Service) for discussions regarding RCW behavior; the US Forest Service (National Forests and Grasslands in Texas), and specifically, D. Carrie and D. Betz, for providing access to data; and E. Taylor for assistance with graphics.

\section{References}

Cale, P.G., Hobbs, R.J., 1994. Landscape heterogeneity indices: problems of scale and applicability, with particular reference to animal habitat description. Pacific Conserv. Biol. 1, 183-193.

Conner, R.N., Rudolph, D.C., 1989. Red-cockaded woodpecker colony status and trends on the Angelina, David Crockett, and Sabine National Forests. US For. Serv. Res. Paper SO-250, 15 pp.

Conner, R.N., Rudolph, D.C., 1991. Forest habitat loss, fragmentation, and red-cockaded woodpecker populations. Wilson Bull. 103, 446-457.

Conner, R.N., Rudolph, D.C., Saenz, D., Coulson, R.N., 1997a. The red-cockaded woodpecker's role in the southern pine ecosystem, population trends and relationships with southern pine beetles. Tex. J. Sci. 49 (suppl.), 139-154.

Conner, R.N., Rudolph, D.C., Schaefer, R.R., Saenz, D., 1997b. Long-distance dispersal of red-cockaded woodpeckers in Texas. Wilson Bull. 109, 157-160.

Coulson, R.N., Fitzgerald, J.W., Oliveria, F.L., Conner, R.N., Rudolph, D.C., 1995. Red-cockaded woodpecker habitat management and southern pine beetle infestations. In: Kulhavy, D.L., Hooper, R.G., Costa, R. (Eds.), Red-Cockaded Woodpecker: Recovery, Ecology and Management, Center for Applied Studies in Forestry Publication, Stephen F. Austin State University, Nacogdoches, TX, USA, pp. 191-195.

Coulson, R.N., Fitzgerald, J.W., McFadden, B.A., Pulley, P.E., Lovelady, C.N., Giardino, J.R., 1996. Functional heterogeneity of forest landscapes: how host defenses influence epidemiology of southern pine beetle. In: Mattson, W.J., Niemila, P., Rossi, M. (Eds.), Dynamics of Forest Herbivory: Quest for Pattern and Principle, USDA Forest Service General Tech. Rpt. NC-183, pp. 272-286.
DeLotelle, R.S., Epting, R.J., Newman, J.R., 1987. Habitat use and home range characteristics of red-cockaded woodpecker in central Florida. Wilson Bull. 99, 202-217.

Ferral, D.P., Edwards, J.W., Armstrong, A.E., 1997. Long-distance dispersal of red-cockaded woodpeckers. Wilson Bull. 109, 154-157.

Forman, R.T.T., 1995. Land Mosaics: The Ecology of Landscapes and Regions, Cambridge University Press, Cambridge, UK, 632 pp.

James, F.C., Hess, C.A., Kufrin, D., 1997. Species-centered environmental analysis: indirect effects of fire history on redcockaded woodpeckers. Ecol. Appl. 7, 118-129.

Kolasa, J., Rollo, C.D., 1991. The heterogeneity of heterogeneity: a glossary. In: Kolasa, J., Pickett, S.T.A. (Eds.), Ecological Heterogeneity, Springer, New York, USA.

Kulhavy, D.L., Hooper, R.G., Costa, R. (Eds.), 1995. RedCockaded Woodpecker: Recovery, Ecology and Management, Center for Applied Studies in Forestry Publication, Stephen F. Austin State University, Nacogdoches, TX, USA, 551 pp.

Lennartz, M.R., Harlow, R.F., 1979. The role of parent and helper red-cockaded woodpeckers at the nest. Wilson Bull. 91, 331335.

Rudolph, D.C., Conner, R.N., 1994. Forest fragmentation and redcockaded woodpecker population: an analysis at intermediate scale. J. Field Ornithol. 65, 365-375.

Rudolph, D.C., Conner, R.N., 1995. The impact of southern pine beetle induced mortality on red-cockaded woodpecker cavity trees. In: Kulhavy, D.L., Hooper, R.G., Costa, R. (Eds.), RedCockaded Woodpecker: Recovery, Ecology and Management, Center for Applied Studies in Forestry Publication, Stephen F. Austin State University, Nacogdoches, TX, USA, pp. 208213.

Rudolph, D.C., Conner, R.N., Carrie, D.K., 1992. Experimental reintroduction of red-cockaded woodpecker. The Auk 109, 914-916.

Thomlinson, J.R., 1993. Landscape ecological characteristics of habitat of the red-cockaded woodpecker (Picoides borealis), Ph.D. Dissertation, University of North Texas, Denton, TX, USA.

Thomlinson, J.R., 1995. Landscape characteristics associated with active and abandoned red-cockaded woodpecker clusters in east Texas. Wilson Bull. 107, 603-614.

Thomlinson, J.R., 1996. Predicting status change in red-cockaded woodpecker cavity-tree clusters. J. Wildl. Manage. 60, 350354.

Turner, M.G., Arthaud, G.J., Engstrom, R.T., Hejl, S., Liu, J., Loeb, S., McKelvey, K., 1995. Usefulness of spatially explicit population models in land management. Ecol. Appl. 5, 12-16.

Walters, J.R., 1991. Application of ecological principles to the management of endangered species: the case of the redcockaded woodpecker. Ann. Rev. Ecol. Syst. 22, 505-523.

Walters, J.R., Copeyon, C.K., Carter III, J.H., 1992. A test for the ecological basis of cooperative breeding in red-cockaded woodpeckers. Auk 109, 90-97.

Walters, J.R., Doerr, P.D., Carter III, J.H., 1988. The cooperative breeding system of the red-cockaded woodpecker. Ethology 78, 275-305. 